\title{
Optimalisasi Alat Praktek Air Conditioning (AC Trainer) pada SMK Ibnu Khaldun Balikpapan
}

\author{
Syaeful Akbar*1, Wahyu Anhar², Nurul Huda³ ${ }^{3}$ Lilik Damayanti , Basri5
}

\author{
1,2,3,5Jurusan Teknik Mesin, Politeknik Negeri Balikpapan, Indonesia \\ 4Jurusan Teknik Sipil, Politeknik Negeri Balikpapan, Indonesia \\ *e-mail: wahyu.anhar@poltekba.ac.id ${ }^{2}$
}

\begin{abstract}
Abstrak
Sekolah Menengah Kejuruan (SMK) merupakan lembaga pendidikan formal yang menitikberatkan pada keterampilan siswa. Lulusan SMK dituntut memiliki keterampilan unggul sehingga mampu bersaing di dunia kerja. Ketersediaan peralatan praktek di SMK sangat penting untuk mewujudkan siswa yang berkompeten. Tidak berfungsinya peralatan air conditioning (AC) trainer di sekolah Ibnu Khaldun Balikpapan menjadi latar belakang dilaksanakannya kegiatan Pengabdian Kepada Masyarakat (PKM) Politeknik Negeri Balikpapan (Poltekba). Kegiatan yang dilaksanakan adalah pengoptimalisasian peralatan AC trainer dengan melakukan pergantian dan perbaikan komponen AC trainer. Secara garis besar rangkaian kegiatan PKM terdiri dari obervasi lokasi, penentuan solusi penyelesaian, pelaksanaan, pengujian dan serah terima alat. Hasil akhir dari kegiatan PKM Poltekba adalah telah dioptimalkannya peralatan AC trainer pada SMK Ibnu Khaldun Balikpapan. Peralatan AC trainer yang telah dapat difungsikan akan membantu siswa untuk mencapai kompetensi pada pelaksanaan praktek AC. Selain itu, juga dihasilkan alat peraga pembelajaran dari komponen AC trainer yang sudah rusak. Komponen yang digunakan sebagai alat peraga pembelajaran adalah compressor dan filter. Alat peraga ini akan membantu siswa untuk mengenal dan mengetahui internal dari kedua komponen.
\end{abstract}

Kata kunci: Air Conditioning, Alat Praktek, Keterampilan, Optimalisasi

Vocational High School (SMK) is the formal educational institution that focuses on student skills. The graduates of SMK are required to have excellent skills to compete in profession. The availability of practice equipment on SMK is important to actualize competent students. Malfunction of air conditioning (AC) trainer equipment at SMK Ibnu Khaldun Balikpapan is the reason of implementation Community Service (PKM) Politeknik Negeri Balikpapan (Poltekba). The activity is optimizing AC trainer equipment by replacing and repairing of AC trainer equipment component. Outline of PKM consist of observing location, determine the solution, implement, testing, and equipment handover. Eventually, PKM Poltekba was able to optimize AC trainer at SMK Ibnu Khaldun Balikpapan. AC trainer equipment that has been able to function will help students to achieve competence in the implementation of AC practice. In addition, learning aids were also produced from damaged AC trainer components. The components used as teaching aids are compressor and filter. This teaching aid will help students to recognize and know the internals of the two components.

Keywords: Air Conditioning, Optimize, Skills, Trainer Equipment

\section{PENDAHULUAN}

Artikel ini disusun berdasarkan kegiatan PKM Poltekba tahun 2021. Kegiatan PKM yang dilaksanakan adalah pengoptimalisasian alat praktek AC trainer pada SMK Ibnu Khaldun Balikpapan. Penentuan lokasi PKM dan solusi penyelesaian berdasarkan hasil kegiatan observasi yang telah dilakukan pada sekolah-sekolah kejuruan di Kota Balikpapan, yang salah satunya adalah SMK Ibnu Khaldun Balikpapan. Minimnya prasarana dan tidak berfungsinya beberapa peralatan praktek di lokasi mitra menjadi kendala dalam pembelajaran praktek bagi siswa. Selain itu, SMK Ibnu Khaldun merupakan sekolah yang terletak di daerah pesisir Kota Balikpapan sehingga keberadaan sekolah sangat dibutuhkan bagi masyarakat sekitar.

SMK merupakan lembaga pendidikan formal yang memfokuskan latihan kerja praktek bagi siswa sehingga terbentuk kecakapan vokasional (kecakapan keterampilan terhadap suatu pekerjaan tertentu) (Amin, 2015). Siswa SMK dituntut untuk memiliki keterampilan unggul 
sehingga mampu bersaing di dunia kerja. Guna mewujudkan keterampilan unggul bagi siswa maka ketersediaan peralatan praktek menjadi penting dalam proses pembelajaran. Peralatan praktek merupakan sarana pendidikan yang secara langsung dipergunakan dan menunjang proses pendidikan. Fasilitas belajar (sarana pendidikan) berpengaruh terhadap proses dan hasil belajar (Susilo dkk., 2015; Wahyuni, 2020). Kelengkapan peralatan praktek akan memudahkan siswa dalam mengerjakan job praktek, sehingga akan meningkatkan prestasi belajar siswa, dan siswa dapat melebihi nilai KKM (Kriteria Kelulusan Minimal) yang harus dicapai (Purwanto \& Suwito, 2016).

Perguruan tinggi dapat berperan dalam menyelesaikan permasalahan-permasalahan lembaga/institusi, masyarakat, lingkungan atau wilayah melalui kegiatan PKM dari masingmasing perguruan tinggi. Beberapa kegiatan PKM berkaitan peralatan/sistem AC telah mampu membantu menyelesaikan permasalahan mitra dan meningkatkan kompetensi peserta (Effendy dkk., 2020; Rahmad dkk., 2021).

Berdasarkan pentingnya ketersediaan dan berfungsinya peralatan praktek bagi siswa SMK serta peran perguruan tinggi, maka tim PKM memberikan solusi penyelesaian dengan mengoptimalisasi peralatan AC trainer yang telah dimiliki SMK Ibnu Khaldun Balikpapan. Optimalisasi peralatan praktek berupa pergantian dan perbaikan komponen AC trainer. Pelatihan singkat terkait perbaikan dan perawatan AC trainer juga diberikan kepada guru mitra sehingga dapat melakukan perbaikan dan perawatan secara mandiri.

\section{METODE}

Rangkaian kegiatan PKM Poltekba seperti ditunjukkan dalam Gambar 1. Kegiatan pendahuluan diawali dengan observasi lokasi oleh Tim PKM yang bertujuan untuk mengetahui kondisi dan situasi dari mitra PKM. Berdasarkan kegiatan observasi lokasi dapat diketahui permasalahan-permasalahan mitra. Apabila dalam kegiatan observasi lokasi tidak ditemukan permasalahan pada mitra, maka tim PKM melakukan observasi pada mitra lainnya. Diskusi dan komunikasi secara aktif dilakukan Tim PKM bersama dengan mitra untuk menentukan solusi penyelesaian. Jika solusi penyelesaian sudah sesuai dengan permasalahan mitra maka Tim PKM melakukan perjanjian kerjasam PKM bersama mitra.

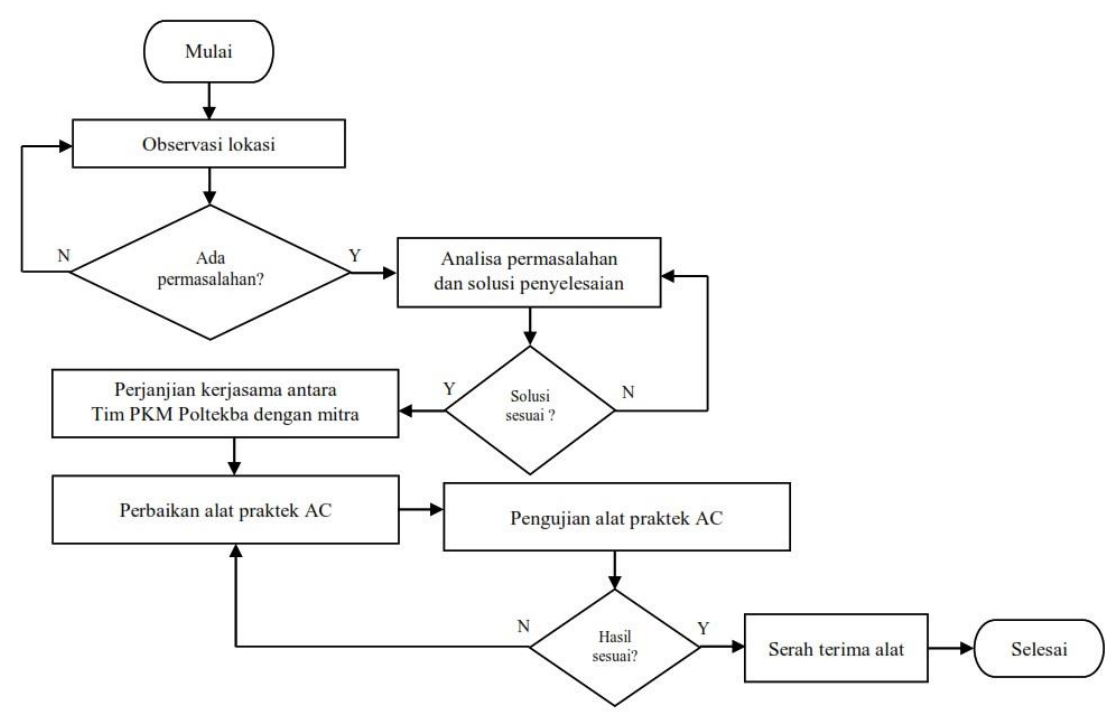

Gambar 1. Alur pelaksanaan PKM

Melanjutkan penjelasan Gambar 1, bahwa proses pelaksanaan PKM dilakukan setelah perjanjian kerjasama antara Tim PKM dengan mitra telah selesai. Pelaksanan PKM secara garis besar adalah pergantian dan perbaikan komponen AC trainer milik mitra. Pergantian komponen dilakukan untuk komponen rusak, sedangkan perbaikan dilakukan untuk komponen atau sistem yang hanya mengalami gangguan fungsi. Setelah dilakukan perbaikan maka AC trainer dilakukan 
pengujian guna memastikan kinerja alat AC trainer telah berfungsi dengan baik. Selain itu, guru pengampu praktek pengkondisian udara di sekolah mitra juga diberikan pelatihan teknis terkait perbaikan dan perawatan AC trainer. Jika proses pengujian alat telah selesai, maka dilanjutkan dengan serah terima AC trainer kepada mitra.

\section{HASIL DAN PEMBAHASAN}

Kondisi awal peralatan praktek AC trainer pada sekolah SMK Ibnu Khaldun seperti ditunjukkan dalam Gambar 2. Terlihat kondisi compressor beserta hose yang tidak dapat digunakan, rangkaian dan komponen kelistrikan untuk simulasi yang putus dan tidak terpasang, filter/drier yang rusak, serta fin condenser yang tidak terawat.

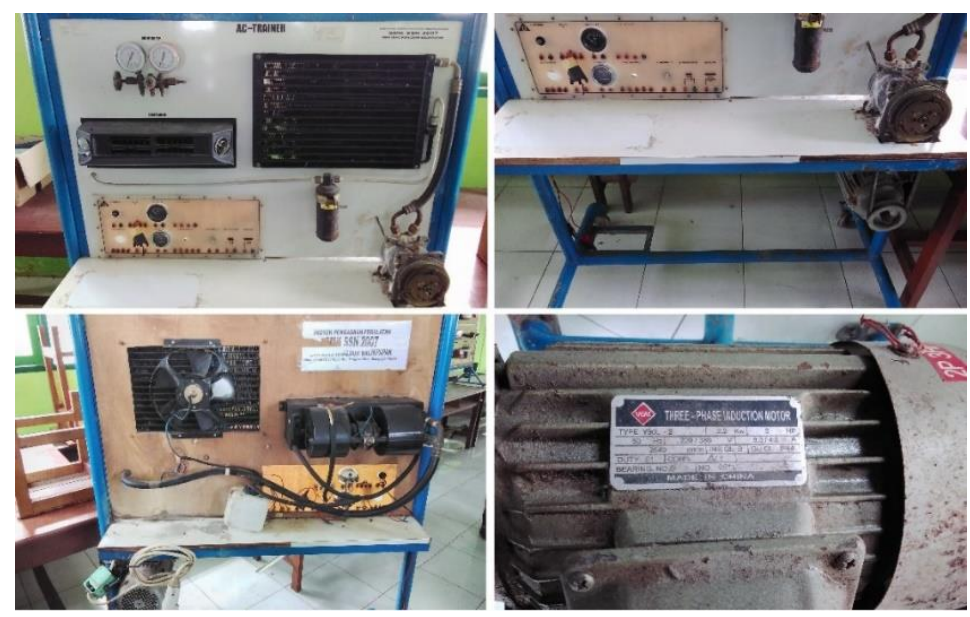

Gambar 2. Kondisi awal AC trainer

Perbaikan diawali dengan melakukan pembongkaran rangkaian AC trainer untuk memudahkan melakukan pengujian dan pemeriksaan komponen secara terpisah. Rangkaian kelistrikan beserta komponen dilakukan pengukuran untuk memastikan sambungan dan kondisi. Hasil pemeriksaan awal didapatkan bahwa motor listrik, compressor, dan filter mengalami kerusakan serta kebocoran pada hose. Selain itu, beberapa komponen kelistrikan ada yang rusak dan putusnya beberapa rangkaian kelistrikan.

Berdasarkan hasil pemeriksaan tersebut maka dilakukan pergantian komponen bagi komponen yang tidak bisa berfungsi, dan perbaikan serta modifikasi untuk komponen/rangkaian yang masih bisa digunakan. Gambar 3 menunjukkan kegiatan pergantian dan perbaikan komponen AC trainer.

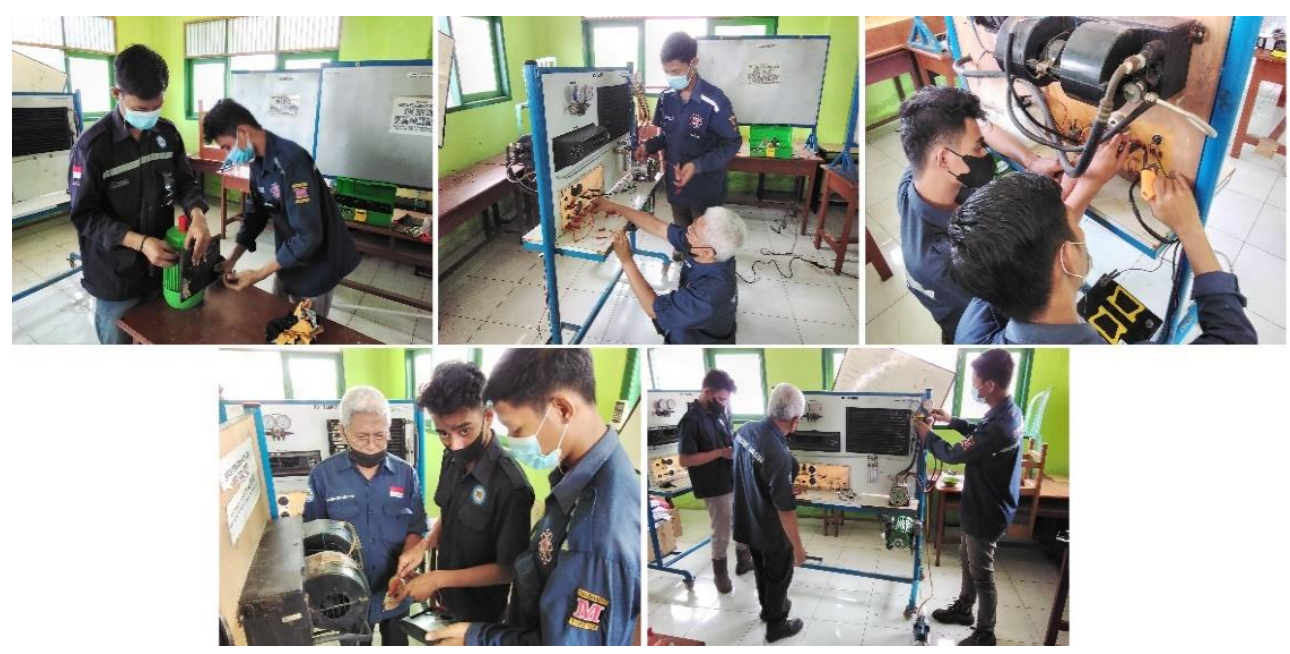

Gambar 3. Pergantian dan perbaikan AC trainer 


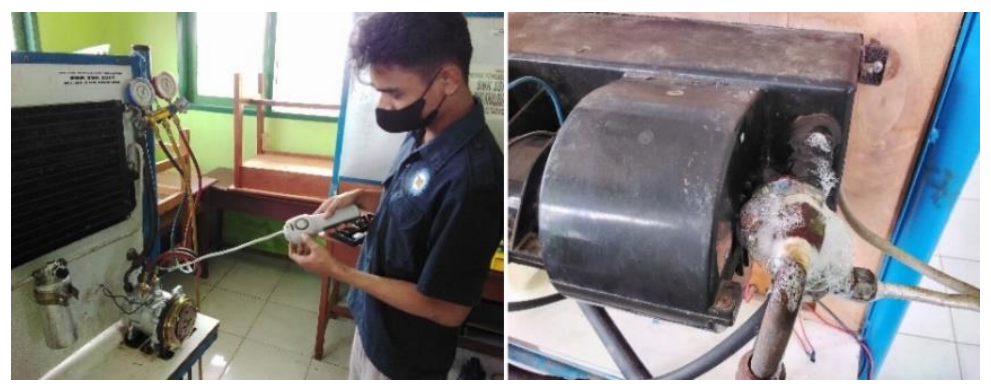

Gambar 4. Pemeriksaan kebocoran gas

Setelah dilakukan pergantian dan perbaikan termasuk pengisian gas refrigerant, maka dilakukan pengujian AC trainer. Pengujian dilakukan terhadap komponen utama AC trainer. Komponen utama pada sistem AC terdiri dari compressor, condenser, evaporator, dan expansion valve (Li dkk., 2017). Pemeriksaan yang juga penting dilakukan adalah pemeriksaan kebocoran gas refrigerant pada sistem AC trainer. Kebocoran gas refrigerant pada sistem AC akan sangat berbahaya bagi lingkungan (Bellos \& Tzivanidis, 2018; Muliawan dkk., 2020; Park dkk., 2019, Srikaummun, 2021). Gambar 4 menunjukkan proses pemeriksaan kebocoran dengan menggunakan leak detector dan juga busa sabun. Setelah peralatan AC trainer lolos pengujian, selanjutnya dilakukan serah terima peralatan kepada SMK Ibnu Khaldun Balikpapan. Gambar 5 menunjukkan kegiatan serah terima peralatan AC trainer kepada SMK Ibnu Khaldun Balikpapan.

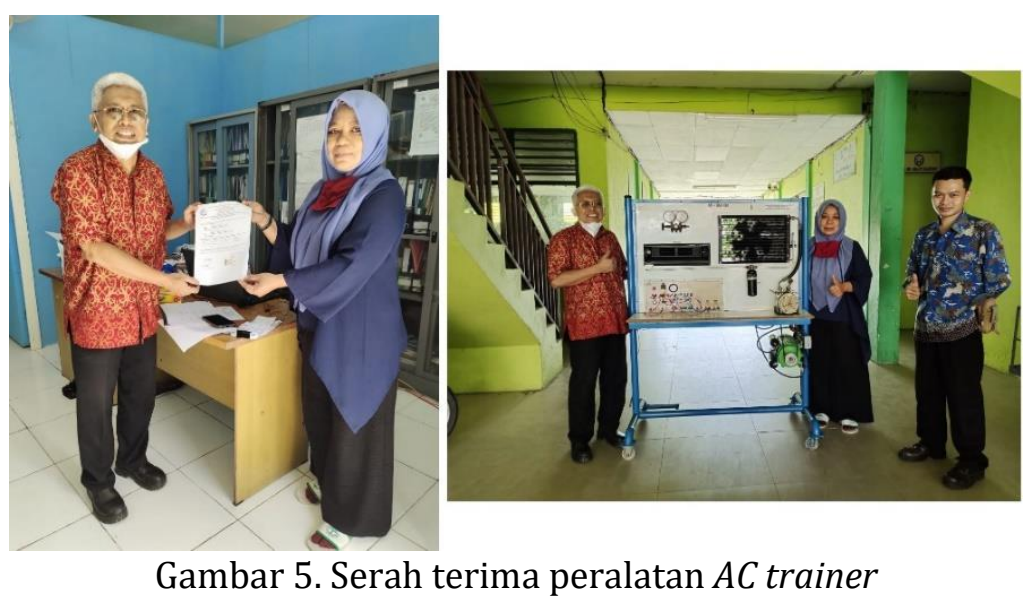

Komponen compressor dan filter yang tidak dapat digunakan, dilakukan pemotongan untuk dijadikan alat peraga pembelajaran, seperti tampak dalam Gambar 6. Melalui media pembelajaran ini siswa dapat mengenal dan mengetahui internal komponen compressor dan filter.

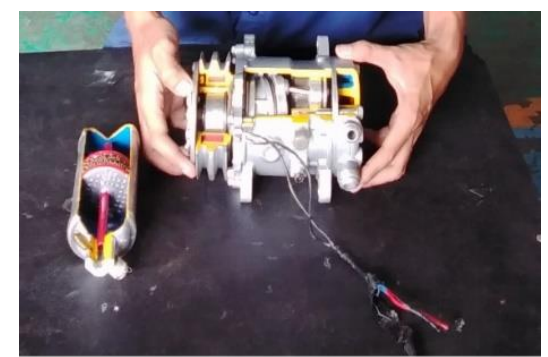

Gambar 6. Hasil pemotongan komponen AC

Berdasarkan kegiatan PKM Poltekba tahun 2021 di SMK Ibnu Khaldun dapat dijabarkan kondisi sebelum dan sesudah pelaksanaan PKM, seperti ditunjukkan dalam Tabel 1. Perbandingan kondisi meliputi aspek kinerja alat, komponen (compressor dan filter), kebocoran, rangkaian listrik (termasuk untuk simulasi), alat peraga pembelajaran, dan dinamo motor. 
Tabel 1. Perbandingan kondisi mitra sebelum dan sesudah PKM

\begin{tabular}{cccc}
\hline No. & Uraian & Kondisi sebelum PKM & Kondisi setelah PKM \\
\hline 1. & Kinerja alat & Tidak berfungsi & Sudah berfungsi \\
2. & Compressor & Rusak & Baik dan baru \\
3. & Filter & Rusak & Baik dan baru \\
4. & Kebocoran & Ada & Tidak ada \\
5. & Rangkaian listrik dan simulasi & Rusak & Baik \\
6. & Alat peraga pembelajaran & Tidak ada & Ada \\
7. & Dinamo motor & 3 fasa & 2 fasa \\
\hline
\end{tabular}

\section{KESIMPULAN}

Kegiatan PKM Poltekba tahun 2021 telah mampu mengoptimalisasikan peralatan AC trainer yang dimiliki SMK Ibnu Khaldun Balikpapan. Peralatan AC trainer yang telah dapat dioperasikan kembali, akan membantu siswa dalam mencapai kompetensi pelajaran pengkondisian udara. Selain itu, kegiatan PKM Poltekba tahun 2021 juga menghasilkan beberapa alat peraga pembelajaran dari komponen compressor dan filter. Alat peraga ini akan membantu siswa untuk dapat mengenal dan mengetahui internal komponen compressor dan filter.

\section{UCAPAN TERIMA KASIH}

Penulis mengucapkan terima kasih kepada Politeknik Negeri Balikpapan yang telah memberi dukungan finansial terhadap kegiatan PKM tahun 2021 ini.

\section{DAFTAR PUSTAKA}

Amin, M. (2015). Ilmu mendidik latihan praktek. Tarbawi, 1(1), 67-76. ISSN: 2442-8809

Bellos, E., \& Tzivanidis, C. (2018). Investigation of the environmentally-friendly refrigerant R152a for air conditioning purposes. Applied Sciences, 9(119), 1-21. doi:10.3390/app9010119

Effendy, M., Saputra, E., \& Surono, A. (2020). Pelatihan perawatan dan perbaikan AC mobil bagi siswa SMK siap lulus. Logista-Jurnal Ilmiah Pengabdian Kepada Masyarakat, 4(2), 63-69. ISSN: 2579-6283

Li, K. Y., Luo, W. J., Huang, J. Z., Chan, Y. C., Pratikto, \& Faridah, D. (2017). Operational temperature effect on positioning accuracy of a single-axial moving carrier. Applied Sciences, 7(420), 1-14. doi:10.3390/app7040420

Muliawan, R., Pasek, A. D., Lukitobudi, A. R., \& Sutandi, T. (2020). Effect of leakage on refrigerant distribution in an air conditioned room using propane as working fluid. IOP Conf. Series: Materials Science and Engineering, 830(042023), 1-7. doi: 10.1088/1757899X/830/4/042023

Park, J., Jung, I., Choi, W., Choi, S. O., \& Han, S. W. (2019). Greenhouse gas emission offsetting by refrigerant recovery from WEEE: a case study on a WEEE recycling plant in Korea. Resources, Conservation \& Recycling, 142, 167-176. https://doi.org/10.1016/j.resconrec.2018.12.003

Purwanto, M. H., \& Suwito, D. (2016). Persepsi siswa tentang kelengkapan peralatan praktek terhadap hasil belajar siswa pada mata diklat dasar kompetensi kejuruan di kelas X SMK Negeri 2 Lamongan. JPTM, 5(1), 50-56.

Rahmad, H., Susanto, R. E. W., Khalida, Z. (2021). Bimbingan teknis pemahaman tentang recovery refrigerant dan efek refrigerant pada kesehatan dan lingkungan pada IKM teknisi AC dan kulkas Kediri Raya. Jasten-Jurnal Aplikasi Sains Teknologi Nasional, 2(2), 16-21. 
Srikaummun, N., Wongsapai, W., Damrongsak, D., Thepsaskul, W., Ritkrekkrai, C., Bunchuaidee, R., Tridech, N., \& Juprasert, P. (2021). Greenhouse gas mitigation and electricity saving potential from replacing refrigerants in Thai refrigerator. Energy Reports, 7, 98-104. https://doi.org/10.1016/j.egyr.2021.07.138

Susilo, H. A., Lie, D., Butarbutar, M., \& Efendi. (2015). Pengaruh fasilitas belajar terhadap kepuasan siswa pada SMK Satrya Budi Karang Rejo. Jurnal MAKER, 1(1), 14-21.

Wahyuni, E. T. (2020). Pengaruh model pembelajaran dan fasilitas belajar terhadap hasil belajar Taruna Akpelni Semarang. Majalah Ilmiah Gema Maritim, 22(1), 67-73. 